\title{
Tick-Borne Illness for Emergency Medicine Providers
}

\author{
Boris Garber $^{1,2}$ • Jonathan Glauser ${ }^{1}$
}

Published online: 13 June 2019

(C) Springer Science+Business Media, LLC, part of Springer Nature 2019

\begin{abstract}
Purpose of Review Ticks are the most important vectors of human diseases after mosquitoes. Emergency physicians throughout the USA can be expected to encounter Lyme disease, Rocky Mountain spotted fever, ehrlichiosis, and other disorders based upon geographic location.

Recent Findings The number of identifiable disorders transmitted by these arthropods has increased in recent years. Severe fever with thrombocytopenia syndrome has only been described within the past decade, and the new millennium has seen over 10 new species of rickettsial disease discovered.

Summary Ticks transmit more pathogenic species than any other group of blood-feeding arthropods. This review provides an update on the diagnosis and management of the diseases most likely to be encountered in clinical practice.
\end{abstract}

Keywords Tick-borne illness $\cdot$ Rocky Mountain spotted fever $\cdot$ Babesiosis $\cdot$ Febrile illness $\cdot$ Lyme disease

\section{Introduction}

Ticks are small, approximately $3-5 \mathrm{~mm}$, with immature forms $0.5-2 \mathrm{~mm}$, arachnid obligate parasites of vertebrates and the most important vector of transmission of zoonotic diseases to humans worldwide and in the USA [1, 2•]. Theobald Smith and Frederick L. Kilborne were the first to show that a tick can transmit an infection to a vertebrate host in 1893 [3]. There are two medically important families: the Argasidae and Ixodidae, commonly known as hard and soft ticks respectively [4]. Hard ticks tend to attach and feed for many hours to days with most parasites only transmitted once the tick has been attached for at least $4 \mathrm{~h}$, while soft ticks feed for minutes at a time often residing in rodents' burrows or birds' nests [5]. Over one third of all species of Ixodidae are known to feed on humans [6]. Mites are tiny arachnids distinct from ticks

This article is part of the Topical Collection on Infectious Disease

Boris Garber

bgarber@metrohealth.org

Jonathan Glauser

jglauser@metrohealth.org

1 Emergency Medicine, Case Western Reserve University, Cleveland, $\mathrm{OH}$, USA

2 Faculty, Residency Program in Emergency Medicine, MetroHealth Medical Center, Cleveland, OH, USA which include some parasitic forms such as Sarcoptes scabiei that causes scabies; infected mouse mites (Liponyssoides sanguineus) which spread rickettsialpox caused by Rickettsia akari; and Leptotrombidium deliense, a form of chiggers which transmits Orientia tsutsugamushi, the cause of scrub typhus. This review will concentrate on tick-borne illness with emphasis on those entities most likely to be encountered by emergency practitioners.

\section{Some Background on Ticks}

Ticks typically undergo three life stages that include a larva that hatches from an egg, a nymph, and an adult, with a blood meal required for each stage of development and additionally one or more for the adult female to lay eggs $[4,6]$. Ticks hunt by positioning themselves on vegetation in a process called questing and respond to stimuli such as carbon dioxide, heat, shadows, and vibrations [2•]. There are a wide range of hosts that ticks parasitize on, facilitating their persistence and spread in the environment.

\section{Human Exposure}

Humans typically play the role of an incidental host for any stage of a tick's development. Humans' exposure to ticks is increased during the warmer part of the year, typically from April to October in the USA. However, tick bites occur even 
in cold weather; Rocky Mountain spotted fever (RMSF) cases are reported to CDC from December to January from the north of the contiguous forty eight states [7•]. The incidence of tickborne illnesses in the USA seems to be increasing [4, 8, 9॰]. This may be due to a number of factors: better surveillance and reporting, increased public and clinician awareness, people spending more time in nature, natural areas incorporated into residential development, an increase in number of tick's hosts such as white tail deer [6], and, possibly, climate warming [10]. Any time a tick acquires a pathogen from an infected host, it can be passed on to the next stage of their development or to the offspring in the developing eggs.

\section{Non-infectious Considerations}

In addition to transmitting bacterial, viral, and protozoan infections, tick bites can rarely result in flaccid paralysis [11], and acute allergic and anaphylactic reactions [12], and even induce meat allergy in patients [13]. Patients can present after a known exposure seeking ways to mitigate a risk of becoming ill, or with a tick-borne illness and no recollection or knowledge of a previous tick bite. Patients can also seek help simply to remove an attached tick. See Table 1 for some noninfectious tick bite-associated medical problems. See Tables 2 and 3 for infectious diseases transmitted by ticks. Table 3 is dedicated to tick-borne viral illnesses, for which treatment is largely supportive.

\section{Management of the Patient with a Reported Tick Bite}

Ticks are ubiquitous in nature and are frequently found in and around homes [17]. Patients can present to the ED either with a tick still attached requiring its removal, or shortly after having removed one themselves seeking ways to reduce chances of developing a tick-borne infectious complication.

\section{Removal of the Attached Tick}

In rare cases of tick-induced anaphylaxis, immediate administration of epinephrine is indicated [13]. This is the only time when killing of the tick in situ with application of ether or dry freezing is recommended prior to its removal $[12,13]$. Otherwise, gentle, steady, upward, and backward pulling on the tick with fine forceps is all that is necessary to remove it. Ixodes ticks cement their mouth parts in the skin with a special substance at the attachment time and if the tick is accidently pulled apart, those parts can be safely left in situ [15]. The site can then be cleaned with rubbing alcohol. Numerous commercial devices are described as aids in tick removal, for example mildly heated forceps or low-energy radiofrequency devices [22] that may decrease the chances of fragmenting the tick.

\section{Prophylaxis Against Infection: Current Status}

No vaccine is currently available in the USA for any of the tick-borne illnesses [7•]. A single $200 \mathrm{mg}$ dose of doxycycline in adults or $4 \mathrm{mg} / \mathrm{kg}$ in children older than 8 years (there is evidence now that doxycycline is safe at any age) may be reasonable after a tick bite is highly endemic for Lyme disease provided it is given within $72 \mathrm{~h}$ of the bite and if the clearly identified Ixodes scapularis tick was attached for at least $36 \mathrm{~h}$ $[14,15]$. The patient should be warned that this does not completely eliminate the chance of Lyme disease development and may not protect from either ehrlichiosis or anaplasmosis which commonly co-infect Ixodes ticks [6, 23].

\section{Management of Selected Tick-Borne Illnesses in the Emergency Department}

Several of tick-borne infectious diseases are both common and mandate an early treatment for an optimal outcome. It is important to recognize that a large proportion of patients with proven tick-borne zoonosis do not recall a tick bite $[5,7 \bullet]$. Ticks' larva and nymph forms are minute, spread pathogens as efficiently as the adults, will fall off to the ground after the feeding, and are commonly overlooked by their human hosts. Some of the tick-borne diseases are caused by bacteria and parasites and have specific therapies recommended (see Table 2).

\section{Lyme Disease}

In the USA, Lyme disease (LD) is the most common vectorborne illness [15] with Borrelia burgdorferi being the pathogen [24]. It may be carried by small rodents such as wild mice and voles, and the disease has an incubation period of 3 20 days. The number of cases has been steadily increasing over the past two decades [25]; the states of Maine, Minnesota, New Hampshire, Vermont, and Virginia now account for over $90 \%$ of all cases [15]. Children aged 5-14 have a higher incidence of LD than adults, and over half of all cases are reported in June and July [15]. Ixodes scapularis ticks are the vectors, and the tick must be attached for at least $36 \mathrm{~h}$ to transmit the pathogen [8].

Similarly to other spirochetal illnesses, Lyme disease occurs in stages. Erythema migrans, an expanding erythematous rash, with or without central clearing, should be greater than $5 \mathrm{~cm}$ in diameter to meet diagnostic criteria, and acute febrile illness are the earliest and most common manifestations. Erythema migrans occurs in $80 \%$ of Lyme disease; it begins at the site of a tick bite after a delay from several to up to 30 days (usually 1 to 2 weeks [8]). Initial localized erythema from local irritation appearing at the tick bite site is not a sign 
Table 1 Non-infectious tick bite-associated medical conditions [1, 2•, 11-14]

\begin{tabular}{|c|c|c|c|}
\hline Problem & Prevention & Management & Comments \\
\hline Attached tick & $\begin{array}{l}\text { Avoidance of areas where ticks } \\
\text { are common such as tall grass } \\
\text { or dense shrubs }[1,2 \cdot] ; \\
\text { protective dress including } \\
\text { closed toe shoes, long sleeve } \\
\text { light clothing with pants } \\
\text { tucked into socks, regular } \\
\text { application of appropriate } \\
\text { insect repellant (DEET } \\
\text { concentration at least } 10 \%, \\
\text { long acting DEET } \\
\text { (ultrathon }{ }^{\text {tm }} \text { ), or picaridin) to } \\
\text { skin and wearing of } \\
\text { permethrin-treated clothing [1, } \\
2 \bullet, 14], \text { regular skin and } \\
\text { clothing checks for ticks }\end{array}$ & $\begin{array}{l}\text { Remove by grasping the tick's } \\
\text { body with fine tweezers and } \\
\text { steady pull backwards and } \\
\text { upwards. Careful avoidance of } \\
\text { squeezing or disturbing the } \\
\text { tick prior to removal to avoid } \\
\text { regurgitation. If tick } \\
\text { anaphylaxis is a concern, } \\
\text { killing the tick with either } \\
\text { permethrin or freeze drying in } \\
\text { situ prior to removal is } \\
\text { recommended }\end{array}$ & $\begin{array}{l}\text { Common areas of attachment } \\
\text { include groin, axilla, and scalp } \\
\text { Many tick-borne illnesses are } \\
\text { not transmitted if the attached } \\
\text { tick is promptly removed. } \\
\text { Only local wound care is } \\
\text { recommended if attached tick's } \\
\text { mouth parts are left behind } \\
\text { unless a wound infection or } \\
\text { foreign body granuloma forms }\end{array}$ \\
\hline Allergic reaction to tick bite & $\begin{array}{l}\text { Avoidance of tick bites, prompt } \\
\text { tick removal }\end{array}$ & $\begin{array}{l}\text { Usual care with early } \\
\text { administration of epinephrine } \\
\text { for anaphylaxis [12]. EpiPen or } \\
\text { similar at discharge }\end{array}$ & $\begin{array}{l}\text { Risk is increased in individuals } \\
\text { with atopy. Severity ranges } \\
\text { from mild local reactions to } \\
\text { exuberant local edema that can } \\
\text { be mistaken for cellulitis, to } \\
\text { anaphylactic shock [13] }\end{array}$ \\
\hline $\begin{array}{l}\text { Tick-induced allergies to } \\
\text { mammalian meat and related } \\
\text { compounds }\end{array}$ & $\begin{array}{l}\text { Avoidance of mammalian meat, } \\
\text { mammalian milks, gelatin, and } \\
\text { gelatin-containing substances } \\
\text { and certain medications (e.g., } \\
\text { cetuximab) [13] }\end{array}$ & & $\begin{array}{l}\text { The mechanism of this acquired } \\
\text { reaction lies in sensitization to } \\
\text { Galactose-alpha-1,3-galactose } \\
\text { (alpha gal) induced by certain } \\
\text { tick's bites [13] }\end{array}$ \\
\hline Tick paralysis & $\begin{array}{l}\text { Regular tick checks and prompt } \\
\text { removal if found especially in } \\
\text { children [11] }\end{array}$ & $\begin{array}{l}\text { Supportive care with ventilator } \\
\text { support may be needed }\end{array}$ & $\begin{array}{l}\text { Rare disease, presenting as } \\
\text { ascending paralysis with } \\
\text { eventual respiratory failure } \\
\text { caused by neurotoxin } \\
\text { produced in salivary glands of } \\
\text { ticks, multiple tick species } \\
\text { implicated worldwide [12] }\end{array}$ \\
\hline
\end{tabular}

of Lyme disease. Additional erythema migrans rashes sometimes appear with the hematogenous spread of Lyme disease.

The second phase, or early disseminated Lyme disease, occurs days to weeks after the tick bite and presents with neurological (especially meningitis and bilateral Bell's palsy) and cardiac findings (classically atrioventricular heart block that can be rapidly progressive or fluctuating from first degree to complete). As erythema migrans and fever commonly resolve by the time of cardiac and neurological manifestations, a careful consideration of the possibility of Lyme disease is necessary as both first degree AV block and a Bell's palsy are typically benign idiopathic conditions. Lyme meningitis clinically resembles that of an aseptic/viral one, with lymphocytic predominance. Serological testing from both blood and cerebrospinal fluid is necessary to confirm the diagnosis [8] in late presenters, while serologic testing is not helpful in a patient with erythema migrans [8].

Late and untreated Lyme disease causes recurring mono(typically knee joint) or oligo-arthritis, and late neuroborr eliosis is also described causing meningoencephalitis or radiculoneuritis [15]. "Chronic" Lyme disease (essentially chronic fatigue and fibromyalgia type disease) or congenital Lyme disease are thought not to exist $[7 \bullet, 8]$ and consequently antibiotic therapy for these patients will not be helpful. Erythema migrans is typically neither painful nor pruritic and so can be overlooked by the patient depending on its location, highlighting the importance of a complete skin exam in a febrile patient. As Lyme disease without erythema migrans has been described, antibiotic treatment should begin if there is a reasonable clinical suspicion while awaiting serologic testing [15].

\section{Lyme Mimic}

The lone star tick Amblyomma americanum bite causes Southern tick-associated rash illness (STARI) heralded by a "bull's eye" rash that is clinically indistinguishable from erythema migrans [8, 14]. It is thought to be an infectious disease, but the cause remains unknown and it follows a uniformly benign course. The only way to distinguish the two is through 


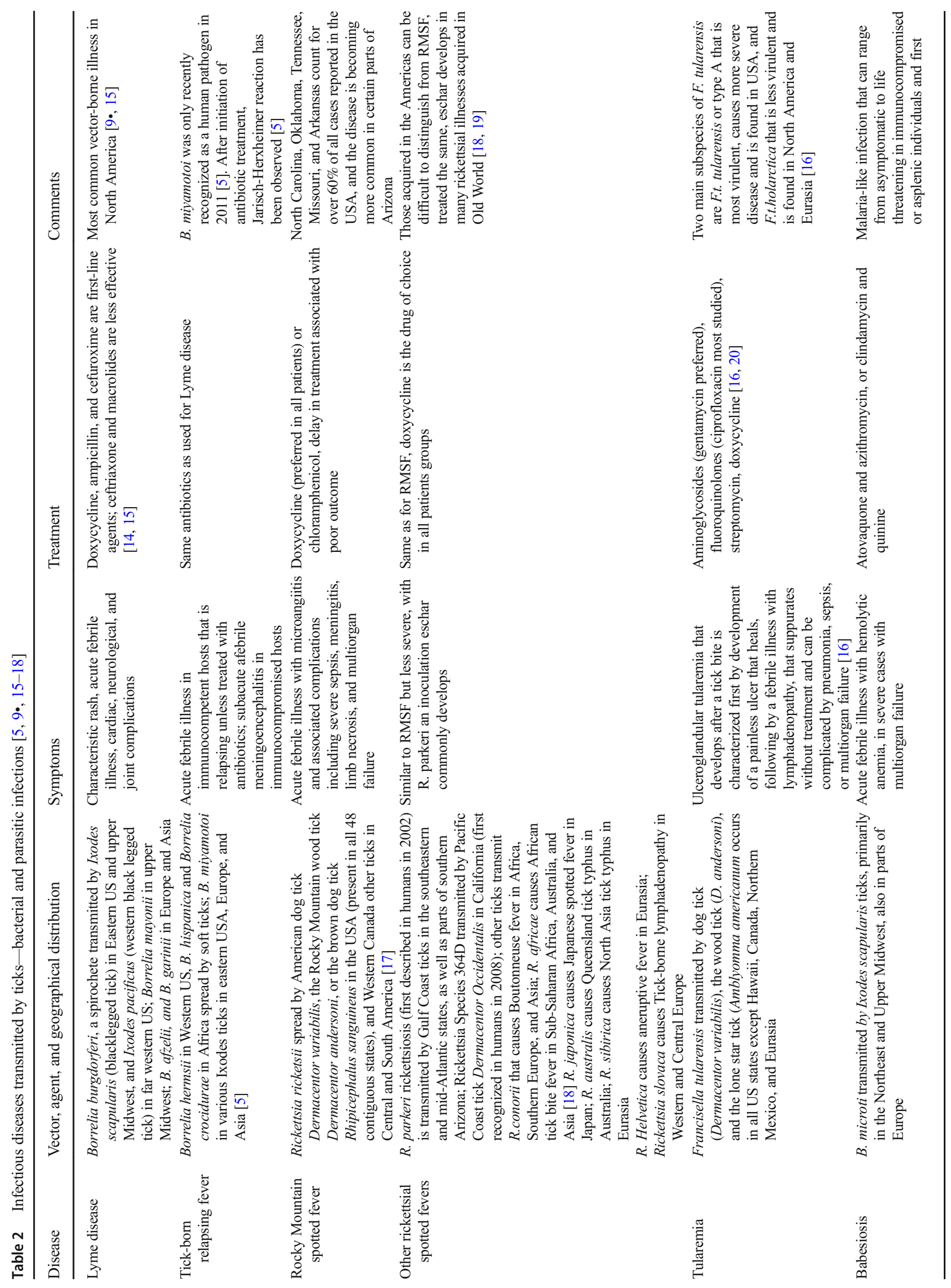




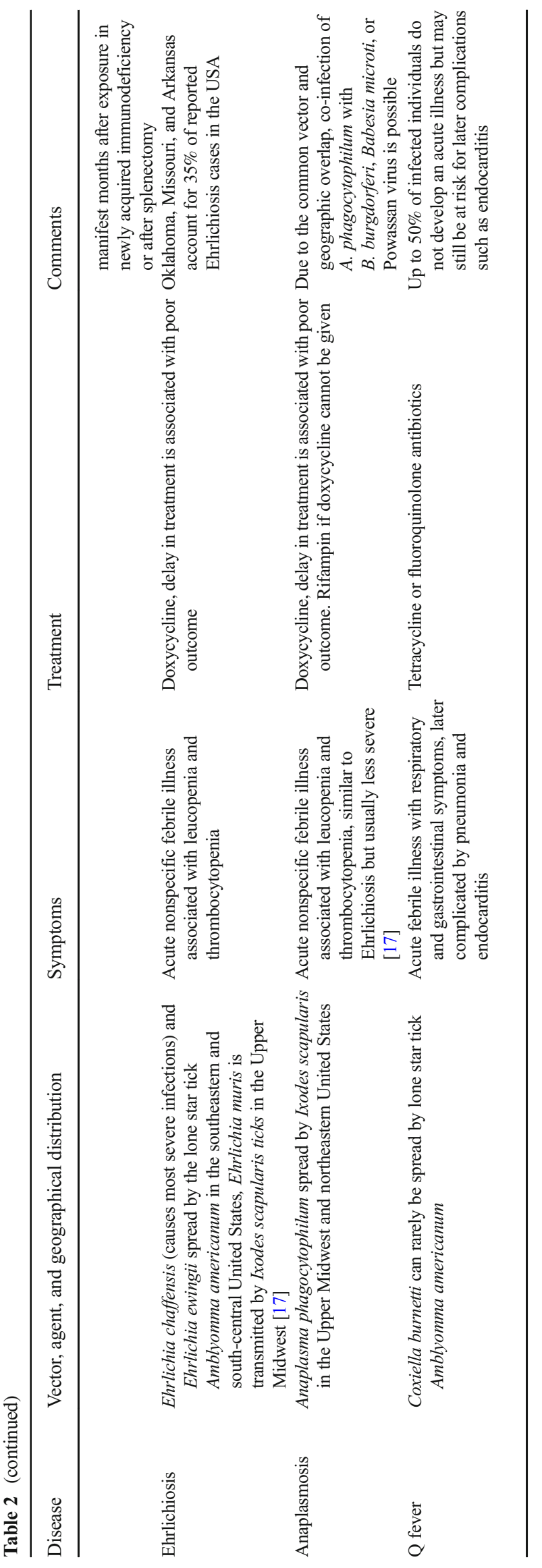

a serologic testing, as the lone star tick' range and Ixodes scapularis' range frequently overlap. Erythema multiforme, arthropod bite reactions, nummular eczema, and granuloma annulare are other potential erythema migrans mimics [8].

\section{Treatment of Lyme Disease}

Once Lyme disease diagnosis is established, the patient should be treated with antibiotics. Diagnosis is confirmed by Western blot testing. Either oral doxycycline, ampicillin, or cefuroxime can be used. In sick patients with neurological or cardiac complications when parenteral antibiotics are needed, ceftriaxone, cefotaxime, or penicillin $\mathrm{G}$ are additional choices. Macrolides are less effective and should only be used if the abovementioned more effective antibiotics cannot be given.

In addition to Borrelia Burgdorferi, Ixodes scapularis ticks are commonly co-infected with several other important human pathogens. In the USA, concurrent babesiosis is seen in up to $20 \%$ of all patients with proven Lyme disease and approximately $10 \%$ are infected with either human granulocytic anaplasmosis agent or Borrelia miyamotoi, the cause of hard tick relapsing fever [5, 24].

\section{Babesiosis}

Human babesiosis is a nationally notifiable disease caused by Babesia microtti in the Northeast and Upper Midwest, Babesia duncani in the Pacific Northwest, and Babesia divergens in Kentucky, Missouri, and Washington State. Babesia spp. are intraerythrocytic protozoan parasites belonging to the same phylum as malaria-causing plasmodiums. Babesia microti is the most common pathogen transmitted by a blood transfusion as reported to the FDA [3], likely due to the large number of subclinical and very mild cases of this infection. Most symptomatic cases manifest anywhere from 1 week to 1 month after the tick bite. High fever and chills are the most common symptoms along with several other nonspecific signs including nonproductive cough, pharyngeal erythema, and conjunctivitis. Splenomegaly, hepatomegaly, and jaundice if present are more helpful in suggesting the clinical diagnosis. Laboratory findings of hemolytic anemia with elevated lactate dehydrogenase levels and reticulocyte counts and thrombocytopenia are usually seen. A definitive diagnosis is made by visualizing parasites on thin blood smear Giemsa or Wright stains or with specialized PCR testing for babesia DNA in blood [14].

\section{Clinical Features of Babesiosis}

Babesiosis clinically ranges from an asymptomatic to a fatal illness mostly depending on the immune status and age of the patient. Asplenic patients, those with HIV infection, lymphoma, those receiving immunosuppressive chemotherapy for 


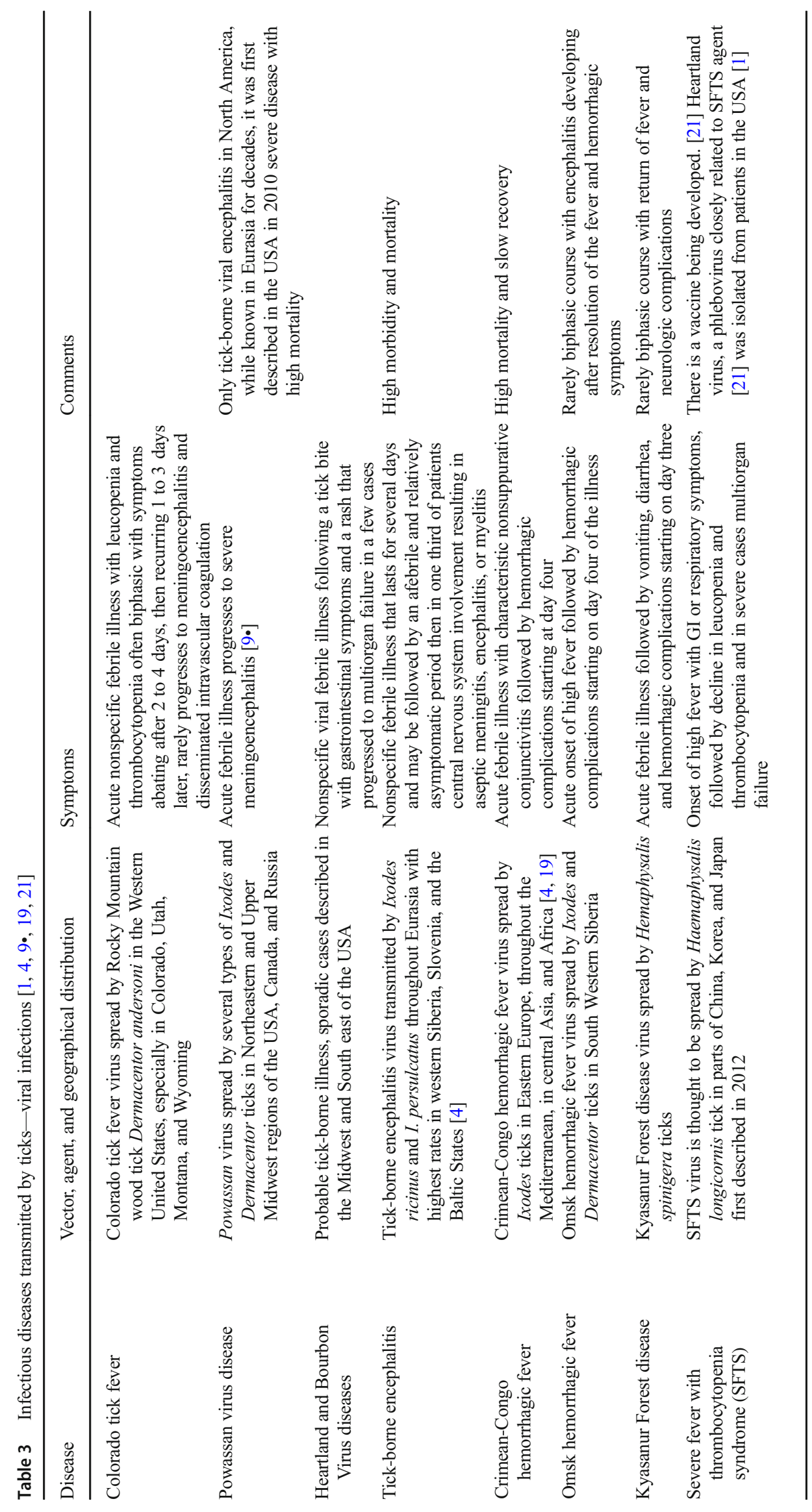


cancer, patients with organ transplantation, or those receiving anticytokine immunomodulating drugs are at risk for severe and fatal disease as are those with severe chronic lung, heart, or liver disease and those at the extremes of age [14]. Acute respiratory distress syndrome, splenic infarct or spontaneous splenic rupture, disseminated intravascular coagulation, coma, and multiorgan failure have been described [3].

\section{Treatment Considerations}

Any symptomatic patient with babesiosis requires treatment. Atovaquone and azithromycin are used for mild to moderate disease and are an option for severe disease while clindamycin with either quinine or quinidine are used for severe disease along with exchange transfusions when high parasitemia or organ failure develops $[3,14]$. Usual treatment duration is 7 to 10 days in immunocompetent patients, while the immunocompromised may require up to 6 weeks of antibiotics.

\section{Anaplasmosis}

Human granulocytic anaplasmosis is caused by Anaplasma phagocytophilum that invades neutrophils and causes a systemic inflammatory response that is the mechanism for tissue damage in this disease [17]. One to 2 weeks after the tick bite, acute febrile illness develops usually without accompanying rash, pronounced gastrointestinal symptoms, or central nervous system involvement. In most cases, it is a self-limiting disease with clinical findings of fever, headache, myalgias, chills, nausea, and abdominal pain; however, the elderly, immunocompromised, and those with severe comorbid conditions are at risk for severe disease. Acute respiratory distress syndrome, hemorrhagic manifestations, acute renal failure, and serious opportunistic viral and fungal infections have been reported [17]. Pancytopenia with left shift and elevated transaminases are the usual laboratory findings.

\section{Diagnosis and Treatment}

PCR, serology, and peripheral blood smear examination looking for intragranulocyte inclusions called morulae establish the diagnosis. Treatment should begin promptly if anaplasmosis is suspected. Doxycycline is the drug of choice in all patients, including children of all ages and pregnant women [17].

\section{Ehrlichiosis}

Similar to human granulocytic anaplasmosis, human monocytic ehrlichiosis is a rickettsial disease found in the southeast and south central United States. This may also be detected by the presence of morulae intracellularly, along with decreased white blood count and thrombocytopenia. Treatment is with doxycycline as well.

\section{Borrelia myamotoi}

Borrelia myamotoi is a recently discovered relapsing fever pathogen that is present in Ixodes ticks, unlike other relapsing fever-causing Borrelia species that are spread by soft-bodied ticks or lice [5]. In immunocompetent hosts, it appears to cause acute febrile illness, usually without a rash, that is relapsing without antibiotic treatment. Leukopenia, thrombocytopenia, and elevated transaminases are characteristic laboratory findings, and PCR on blood or cerebrospinal fluid can be diagnostic during an acute infection. In immunocompromised patients, a progressive afebrile meningoencephalitis was reported. Antibiotics used in treatment of Lyme disease appear to be uniformly effective in curing Borrelia myamotoi relapsing fever [25].

\section{Tularemia}

Tularemia, caused by the agent Francisella tularensis, may be transmitted by contaminated water, contact with contaminated animals, or by tick bites. It is listed also as a category A bioterrorism agent. Specific symptoms are listed in Table 2. It is treatable with streptomycin, gentamicin, ciprofloxacin, or doxycycline.

\section{Tick-Borne Viral Illness}

A variety of viruses have been reported as tick-borne illness and are listed in Table 3. Tick-borne encephalitis is a flavivirus, and the most important tick-borne illness in Europe. Crimean-Congo hemorrhagic fever has the largest known distribution of any tick-transmitted virus, ranging from the Crimea through Eastern Europe, Iran, and India. Powassan disease agent is another flavivirus, notable because it is fatal in $10 \%$ of patients who develop encephalitis. In 2010, severe fever with thrombocytopenia syndrome (SFTS) was described in China, then 2 years later in Korea and Japan. The causative agent is a phlebovirus, which causes a hemorrhagic fever, a case fatality rate of approximately $7 \%$ due to multiorgan failure, and an average time to death of 9 days. The treatment is supportive.

\section{Rocky Mountain Spotted Fever}

Rocky Mountain spotted fever (RMFS) is the most common and severe of the rickettsial infections in the USA. It is caused by Rickettsia rickettsii that is transmitted by American dog tick Dermacentor variabilis, the Rocky Mountain wood tick Dermacentor andersoni, or the brown dog tick Rhipicephalus sanguineus. Only 
Table 4 Selected antibiotics used in treatment of tick-borne illnesses $[8,14,17,20]$

\begin{tabular}{|c|c|c|}
\hline Antibiotic & Indications & Dosing and duration \\
\hline Doxycycline & $\begin{array}{l}\text { Lyme disease, other borreliosis, tick-borne rickettsiosis } \\
\text { including RMSF, human granulocytic anaplasmosis, } \\
\text { ehrlichiosis, tularemia (second line) }\end{array}$ & $\begin{array}{l}100 \mathrm{mg} \text { BID or } 2.2 \mathrm{mg} / \mathrm{kg} / \mathrm{dose} \text { up to } 100 \mathrm{mg} \text { BID for } \\
\text { children 10-21 days }\end{array}$ \\
\hline Chloramphenicol & Second (and inferior) choice for RMSF & $\begin{array}{l}25-50 \mathrm{mg} / \mathrm{kg} \text { every } 6 \mathrm{~h} \text { max single dose is } 1 \mathrm{~g} \text {, } \\
\text { monitor serum concentration }\end{array}$ \\
\hline Atovaquone & $\begin{array}{l}\text { Together with azithromycin for mild or moderate } \\
\text { babesiosis }\end{array}$ & $\begin{array}{l}750 \mathrm{mg} \text { BID for } 7-10 \text { days; up to } 6 \text { weeks in severely } \\
\text { immunocompromised patients }\end{array}$ \\
\hline Quinine & Together with clindamycin for severe babesiosis & $650 \mathrm{mg}$ orally $3-4$ times a day for $7-10$ days \\
\hline Rifampin & $\begin{array}{l}\text { Human granulocytic anaplasmosis if doxycycline is } \\
\text { absolutely contraindicated }\end{array}$ & $\begin{array}{l}10-20 \mathrm{mg} / \mathrm{kg} \text { max } 600 \mathrm{mg} \text { daily for } 7-10 \text { days. Nor } \\
\text { active against Lyme disease or rickettsial illnesses }\end{array}$ \\
\hline Gentamycin & Severe tularemia & $\begin{array}{l}\text { Once daily } 5 \mathrm{mg} / \mathrm{kg} \text { with serum concentration } \\
\text { monitoring for } 10-21 \text { days }\end{array}$ \\
\hline Ciprofloxacin & Mild to moderate tularemia & $500 \mathrm{mg}$ PO BID for $7-10$ days \\
\hline
\end{tabular}

approximately a half of patients diagnosed with RMFS recall a tick bite [17]. Delayed diagnosis or providing inappropriate antibiotic therapy for this illness increases the chances of a fatal outcome. It is transmitted everywhere in the USA except for Alaska and Hawaii, with Arkansas, Missouri, North Carolina, and Tennessee, accounting for over half of all reported cases. Most patients are seen from April to October [26]. At least 4 to $6 \mathrm{~h}$ of tick attachment is needed for disease transmission and only $1-3 \%$ of ticks in the endemic areas carry the bacteria, so prophylactic antibiotics to prevent RMSF are not recommended [26].

\section{RMSF Signs and Symptoms}

RMSF is an acute infectious vasculitis affecting small and medium blood vessels, accounting for the wide range of disease manifestations. After an incubation period from 2 to 14 days, an acute nonspecific febrile illness ensues with a variety of accompanying symptoms. These are classically accompanied by a severe headache. The initially macular rash begins on the wrists and ankles 2 to 5 days after fever onset. The rash spreads centrally, and eventually can develop into petechiae and purpura with tissue necrosis. The rash may be absent in up to $15 \%$ of cases and many patients seek care before the development of rash $[17,26]$. Complications may occur early in severe cases and include meningoencephalitis, myocarditis, acute respiratory distress syndrome, rhabdomyolysis, and vascular vision loss. In its early stages, RMFS is a clinical diagnosis and requires a good travel and exposure history. Routine laboratory testing may reveal normal or slightly increased leucocyte count, mild thrombocytopenia, and hyponatremia. Antibody testing to Rickettsia ricketsii is the current diagnostic standard but is sensitive only after 7 to 10 days after disease onset [26].

\section{RMSF Differential Diagnosis}

Severe RMFS differential diagnosis includes meningoc occemia, other severe bacterial sepsis, or systemic vasculitis from other causes. Once RMSF is reasonably suspected and cannot be confidently ruled out by showing a presence of a different pathological process, treatment should be implemented without delay (Table 4). The antibiotic of choice in adult and pediatric patients regardless of age is doxycycline $[17,26]$. The safety data for use of doxycycline in pregnancy is lacking, but a short course has been deemed to be likely safe [17]. Patients treated with chloramphenicol, the only other agent with activity against Rickettsia rickettsia, are at higher risk of death [17]. Use of chloramphenicol may only be appropriate in case of severe tetracycline allergy when rapid desensitization is impossible due to the nature of reaction (i.e., Stevens-Johnson) or possibly in pregnancy with joint decision-making [26]. While cephalosporins, aminoglycosides, and broad spectrum $\beta$ lactams have no activity against RMFS pathogen, they may need to be administered to a sick septic patient initially while the diagnosis is established.

\section{Conclusions}

Ticks are ubiquitous in the USA and are especially active during warm weather; close to 1000 species have been described. Tick bite prevention may entail use of $\mathrm{N}$. N diethylm-toluamide (DEET), picardin, permethrin-impregnated clothing, and gloves with protective clothing to prevent blood exposure. People frequently are unaware of being bitten by a tick. Prompt removal of an attached tick is likely protective. While some tick-borne illnesses are caused by viruses, warranting only supportive care, others are caused by rickettsial diseases and by parasites which mandate prompt and specific directed care. 
It is prudent to consider several tick-borne bacterial illnesses in patients presenting with acute nonspecific febrile illness, including those who do not recall a recent tick bite. Early diagnosis and treatment may prevent serious complications, including death. All common treatable infectious tickborne illnesses common in the USA, except for babesiosis, can be effectively treated with doxycycline, and it is likely that doxycycline can be given safely to patients of any age when necessary.

Acknowledgments The authors wish to thank Dr. James Paxton for reviewing their manuscript.

\section{Compliance with Ethical Standards}

Conflict of Interest The authors declare that they have no conflict of interest.

Human and Animal Rights and Informed Consent This article does not contain any studies with human or animal subjects performed by any of the authors.

\section{References}

Papers of particular interest, published recently, have been highlighted as:

- Of importance

1. Liu Q, He B, Huang S-Y, et al. Severe fever with thrombocytopenia syndrome, an emerging tick-borne zoonosis. Lancet Infect Dis. 2014;14(8):763-72.

2. Pages F, Dautel H, Duvallet G, Kahl O, de Gentile L, Boulanger N. An excellent overview of prevention of tick-born illness, with repellants and how the maximize their effectiveness. Tick repellents for human use: prevention of tick bites and tick-borne diseases. Vector Borne Zoonotic Dis. 2014;14(2):85-93.

3. Vannier E, Krause PJ. Human babesiosis. N Engl J Med. 2012;366: 2397-407.

4. Estrada-Peña A, de la Fuente J. The ecology of ticks and epidemiology of tick-borne viral diseases. Antivir Res. 2014;108:104-28.

5. Wagemakers A, Staarink PJ, Sprong H, et al. Borrelia miyamotoi: a widespread tick-borne relapsing fever spirochete. Trends Parasitol. 2015;31(6):260-9.

6. Pfäffle M, Littwin N, Muders SV, et al. The ecology of tick-borne diseases. Int J Parasitol. 2013;43(12-13):1059-77.

7. Buckingham SC. Tick-borne diseases of the USA: ten things clinicians should know. J Infect. 2015;71(Supplement 1):88-96 A common sense approach to the patient with possible tick-borne illness, from a clinical perspective.

8. Shapiro ED. Lyme disease. N Engl J Med. 2014;370:1724-31.

9. Paules CI, Marston HD, Bloom ME. Tickborne diseasesconfronting a growing threat. N Engl J Med. 2018;379:701-3 An outstanding overview of standard of care and the magnitude of the problem of tick-borne illness.

10. Andersen LK, Davis MDP. Climate change and the epidemiology of selected tick-borne and mosquito-borne diseases: update from the International Society of Dermatology Climate Change Task Force. Int J Dermatol. 2017;56(3):252-9.

11. Chagnon SL, Naik M, Abdel-Hamid H. Child neurology: tick paralysis. Neurology. 2014;82(11):91-3.

12. Rappo TB, Cottee AM, Ratchford AM, Burns BJ. Tick bite anaphylaxis: incidence and management in an Australian emergency department. Emerg Med Australas. 2013;25(4):297-301.

13. Van Nunen S. Tick-induced allergies: mammalian meat allergy, tick anaphylaxis and their significance. Asia Pac Allergy. 2015;5(1):316.

14. Sanchez E, Vannier E, Wormser GP, Hu LT. Diagnosis, treatment, and prevention of Lyme Disease, human granulocytic anaplasmosis, and babesiosis: a review. JAMA. 2016;315(16):1767-77.

15. Applegren ND, Kraus CK. Lyme disease: emergency department considerations. J Emerg Med. 2017;52(6):815-24.

16. Ulu-Kilic A, Doganay M. An overview: tularemia and travel medicine. Travel Med Infect Dis. 2014;12(6, Part A):609-16.

17. Biggs HM, Behravesh CB, Bradley KK, et al. Diagnosis and management of tickborne rickettsial diseases: Rocky Mountain spotted fever and other spotted fever group Rickettsioses, Ehrlichioses, and Anaplasmosis - United States A practical guide for health care and public health professionals. MMWR. 2016;65(2):1-44.

18. Binder WD, Gupta R. African tick-bite fever in a returning traveler. J Emerg Med. 2015;48(5):562-5.

19. Thwaites GE, Day NPJ. Approach to fever in the returning traveler. N Engl J Med. 2017;376:548-60.

20. Boisset S, Caspar Y, Sutera V, Maurin M. New therapeutic approaches for treatment of tularaemia: a review. Front Cell Infect Microbiol. 2014;4:40.

21. Reece LM, Beasley DWC, Milligan GN, et al. Current status of severe fever with thrombocytopenia syndrome vaccine development. Curr Opin Virol. 2018;29:72-8.

22. Ashique KT, et al. Radiofrequency device for tick removal. J Am Acad Dermatol. 72(6):155-6.

23. Egizi A, Fefferman NH, Jordan RA. Relative risk for ehrlichiosis and Lyme Disease in an area where vectors for both are sympatric, New Jersey, USA. Emerg Infect Dis. 2017;23(6). https://doi.org/10. 3201/eid2306.160528

24. Diuk-Wasser MA, Vannier E, Krause PJ. Coinfection by tick-borne pathogens Babesia microti and Borrelia burgdorferi: ecological, epidemiological, and clinical consequences. Trends Parasitol. 2016;32(1):30-42.

25. Kugeler KJ, Farley GM, Forrester JD, Mead PS. Geographic distribution and expansion of human Lyme Disease, United States. Emerg Infect Dis. 2015;21(8):1455-7.

26. Gottlieb M, Long B, Koyfman A. The evaluation and management of Rocky Mountain spotted fever in the emergency department: a review of the literature. J Emerg Med. 2018;55(1):42-50.

Publisher's Note Springer Nature remains neutral with regard to jurisdictional claims in published maps and institutional affiliations. 